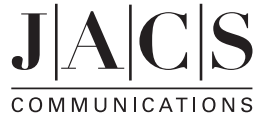

Published on Web 11/02/2005

\title{
Large-Scale Ni-Doped ZnO Nanowire Arrays and Electrical and Optical Properties
}

\author{
Jr H. He, ${ }^{\dagger, \ddagger}$ Chang S. Lao, ${ }^{\dagger}$ Lih J. Chen, ${ }^{\star \neq}$ Dragomir Davidovic,,$^{\S}$ and Zhong L. Wang ${ }^{\star, \dagger}$ \\ School of Materials Science and Engineering, Georgia Institute of Technology, Atlanta, Georgia 30332-0245 USA, \\ Department of Materials Science and Engineering, National Tsing Hua University, Hsinchu, Taiwan 300, ROC, and \\ School of Physics, Georgia Institute of Technology, Atlanta, Georgia 30332-0430 USA
}

Received August 27, 2005; E-mail: zhong.wang@mse.gatech.edu; ljchen@mx.nthu.edu.tw

Wurtzite-structured $\mathrm{ZnO}$ has versatile properties that are important for applications in electronics, optoelectronics, photovoltaics, and sensors. ${ }^{1}$ Recently, one-dimensional (1D) nanostructures of $\mathrm{ZnO}$, such as nanowires (NWs), nanorods (NRs), nanobelts, and nanotubes, are attracting much interest. ${ }^{2}$ It is highly desired to grow 1D nanomaterials that have not only controlled shapes and crystal structure but also designed electrical and optical properties for applications as sensors, field-emitters, $\mathrm{p}-\mathrm{n}$ diodes, and the diluted magnetic semiconductors (DMS) for spintronics. ${ }^{3}$ A key requirement for many of these applications is the doping of $\mathrm{ZnO}$ with various elements for enhancing and controlling its electrical and optical performance. . $^{3 \mathrm{c}, \mathrm{g}, 4}$

In this paper, large-scale $\mathrm{Ni}$-doped $\mathrm{ZnO} \mathrm{NW}$ arrays are prepared for the first time using a metal vapor vacuum arc (MEVVA) ion source doping technique. ${ }^{5}$ By measuring the transport property of a single NW across two electrodes, the electrical conductivity of the doped $\mathrm{ZnO} \mathrm{NW}$ has been increased for 30 times after doped to a dose of $2 \times 10^{17} \mathrm{~cm}^{-2}$. The photoluminescence (PL) spectrum of the doped $\mathrm{ZnO} \mathrm{NW}$ s has a red shift, suggesting possible doping induced band edge bending. The doped $\mathrm{ZnO} \mathrm{NW}$ arrays could be the basis for building integrated nanoscale transistors, sensors, and photodetectors.

In the vapor-liquid-solid (VLS) growth, ${ }^{6}$ a nominally 2-nmthick $\mathrm{Au}$ thin film was deposited onto (11-20) $\mathrm{Al}_{2} \mathrm{O}_{3}$ substrate and served as the catalyst for the VLS growth. The experimental apparatus has been described in a previous study. ${ }^{7}$ A mixture of commercial $\mathrm{ZnO}$ and graphite powders in a ratio of $\mathrm{Zn}: \mathrm{C}=4: 1$ was placed in an alumina boat, which was heated to a peak temperature of $1100{ }^{\circ} \mathrm{C}$. The $\mathrm{Al}_{2} \mathrm{O}_{3}$ substrate was placed at a temperature zone of $\sim 800{ }^{\circ} \mathrm{C}$ for collecting $\mathrm{ZnO}$ nanostructures. After the tube had been evacuated to a pressure of $1 \times 10^{-3}$ Torr, the samples were heated to $1100{ }^{\circ} \mathrm{C}$ and held at $1100{ }^{\circ} \mathrm{C}$ for 60 min with a carrier gas of $\mathrm{Ar}+\mathrm{O}_{2}$ flowing through the tube.

Without any treatment, the well-aligned $\mathrm{ZnO}$ NWs were directly doped by MEVVA with $\mathrm{Ni}$ ion at a dose of $2 \times 10^{17} \mathrm{~cm}^{-2}$ and an incident angle of $5^{\circ}$ with the vertical NWs (see Figure 1a), at an extraction voltage of $100 \mathrm{kV}$ and at $200{ }^{\circ} \mathrm{C}$. The doped samples were then treated by thermal annealing at $950{ }^{\circ} \mathrm{C}$ for $2 \mathrm{~h}$ in $\mathrm{O}_{2}$ ambient for eliminating the doping-induced defects.

After the annealing process, the substrate-bound NWs were mechanically scrapped off and sonicated in ethanol and deposited on a grid for transmission electron microscope (TEM) characterization. To perform electrical measurements, the NW devices were fabricated by electron beam lithography with lift-off technique. The PL properties of the synthesized NWs were studied at room temperature using a $\mathrm{He}-\mathrm{Cd}$ laser in the spectral range of 350$800 \mathrm{~nm}$ with an excitation wavelength of $325 \mathrm{~nm}$.

$\dagger$ School of Materials Science and Engineering, Georgia Institute of Technology

\#ational Tsing Hua University.

$\S$ School of Physics, Georgia Institute of Technology.

16376 - J. AM. CHEM. SOC. 2005, 127, 16376-16377

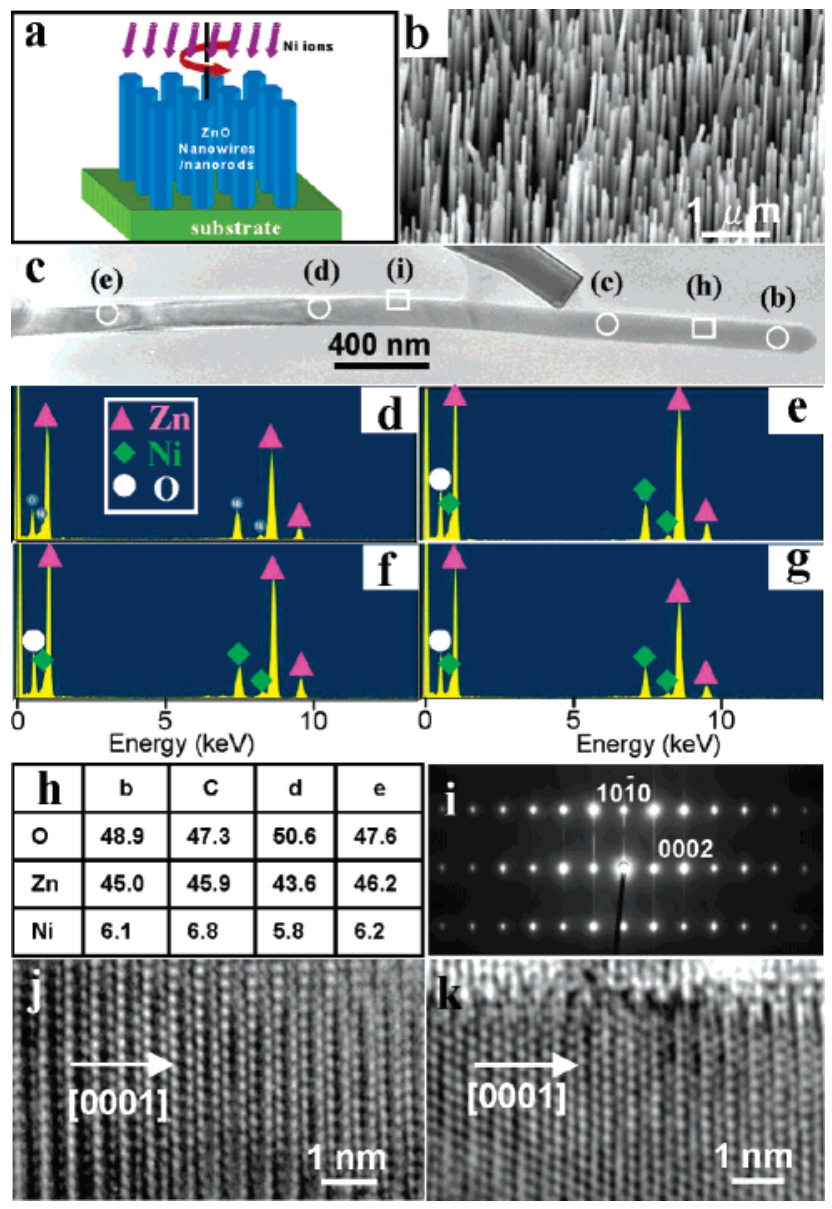

Figure 1. Electron microscopy characterization of the Ni-doped $\mathrm{ZnO} \mathrm{NW}$. (a) The schematic setup for ion doping; (b) an SEM image of the wellaligned $\mathrm{ZnO} N W s$. (c) TEM image of the ZnO NWs. (d-g) EDS spectra acquired from the areas labeled with $\mathrm{d}, \mathrm{e}, \mathrm{f}$, and $\mathrm{g}$ in (c). (h) The composition (in atom \%) distribution along the NW at the labeled positions determined from EDS microanalysis. (i) The corresponding selected area electron diffraction pattern from the NW shown in (a). (j, k) HRTEM images from the outlined areas in (c).

Figure $1 \mathrm{~b}$ is the well-aligned, Ni-doped $\mathrm{ZnO} \mathrm{NWs}$, showing fairly uniform morphology. After the doping process and post-doping annealing, the distribution of $\mathrm{Ni}$ dopants and structure of the $\mathrm{ZnO}$ NW were studied by TEM in conjunction with energy-dispersive $\mathrm{X}$-ray spectroscopy (EDS). Figure 1c shows that there are no visible defects, second phase, or precipitation in the Ni-doped $\mathrm{ZnO}$ NWs. It means that, after a proper annealing, the crystal lattice structure of the NW is fully recovered and the dopants are well-integrated into the lattice sites. EDS spectra from a series of locations along one $\mathrm{ZnO}$ NW as labeled in Figure 1c are displayed in Figure 1d$\mathrm{g}$, respectively, and the quantitative elemental distribution in atomic 


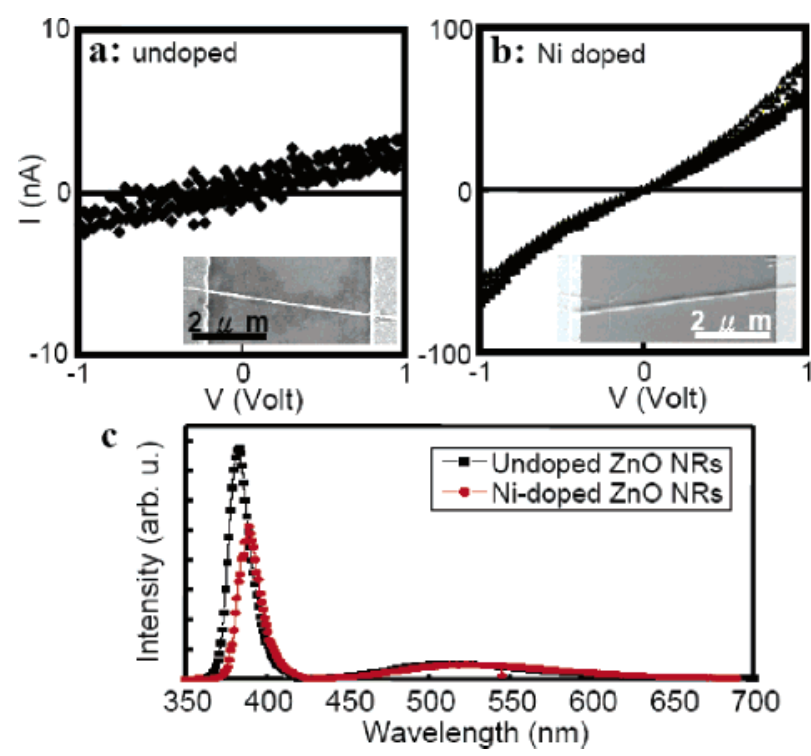

Figure 2. $I-V$ characteristics of an (a) undoped $\mathrm{ZnO} \mathrm{NW}$ and (b) a $\mathrm{Ni}$ doped NW measured by repeatedly scanning the bias from -1 to $1 \mathrm{~V}$. (c) A comparison of the PL spectra for the undoped and Ni-doped $\mathrm{ZnO}$ NWs.

percentage is tabled in Figure $1 \mathrm{~h}$. The $\mathrm{Zn}$ and $\mathrm{O}$ signals of the NWs as well as the Ni signal were observed along the entire length. With consideration of the accuracy of the EDS microanalysis, we can conclude that there is $\sim 6$ atom $\% \mathrm{Ni}$ doping in the $\mathrm{ZnO} \mathrm{NW}$. The annealing procedure at $950{ }^{\circ} \mathrm{C}$ resulted in a fairly uniform distribution of the doped $\mathrm{Ni}$ atoms. The corresponding selected area electron diffraction (SAED) pattern from a single doped NW, as shown in Figure 1i, confirms that the NWs have the wurtzite structure and there is no formation of a Ni precipitated secondary phase. The crystal lattice structure of the NW has also been examined by high-resolution TEM (HRTEM). Both the lattice images recorded from the center (Figure 1j) and the side (Figure $1 \mathrm{k}$ ) of the NW clearly show the high crystallinity of the NW with no visible line or planar defects. The diffusion of $\mathrm{Ni}$ ion in $\mathrm{ZnO}$ and recovery of doped $\mathrm{ZnO}$ crystal are most probably due to the high-temperature, long-time annealing as well as ultra large surface area of the NW. Our observed results are consistent with the studies claiming a complete removal of all doping-induced defects in $\mathrm{ZnO}$ thin films and the activation of the doped species after annealing. ${ }^{8}$

It is known that the as-synthesized and undoped $\mathrm{ZnO}$ NWs are the n-type semiconductor due to high density of oxygen vacancies. The typical current-voltage $(I-V)$ curve through a single undoped $\mathrm{ZnO} N W$ is given in Figure 2a. The current changed linearly from about -3 to $3 \mathrm{nA}$ as $V$ was varied from -1 to $1 \mathrm{~V}$ with a resistivity $\rho$ of $390 \Omega \mathrm{cm}$. High electrical resistivity in a single undoped $\mathrm{ZnO}$ NW indicates its high quality of crystalline structure with low oxygen deficiencies. ${ }^{9}$ This result has been further confirmed by our PL measurement performed on undoped ZnO NWs (Figure 2c). In contrast, the $I-V$ curve for a Ni-doped $\mathrm{ZnO} \mathrm{NW}$ (Figure 2b) shows a steep increase in conductance, indicating a great enhancement in conductivity by doping. The current of the doped NW changed from about -75 to $75 \mathrm{nA}$ as the voltage $V$ was varied from -1 to $1 \mathrm{~V}$, and the resistivity drops to $12 \Omega \mathrm{cm}$. For thin films, doping of cations of higher valence state than $\mathrm{Zn}\left(\mathrm{Zn}^{2+}\right)$ into $\mathrm{ZnO}$, such as $\mathrm{In}, \mathrm{Ga}$, and $\mathrm{Ni}$, leads to an increase in the electrical conductivity. ${ }^{2}$ Referred to the pure undoped $\mathrm{ZnO} \mathrm{NW}$, the doped $\mathrm{Ni}$ enhances the conductivity probably due to the presence of trivalent $\mathrm{Ni}^{3+}$ cations. $\mathrm{A} \mathrm{Ni}^{3+}$ cation would contribute a hole carrier, and the oxygen vacancies are likely to be eliminated by annealing in air at high temperature; therefore, the possible carriers are p-type. $^{2 \mathrm{~d}}$

Figure 2c shows PL spectra of ZnO NWs before and after doping. The UV emission peak is centered at $389 \mathrm{~nm}$ for the Ni-doped $\mathrm{ZnO}$ NWs, which exhibits a red shift of $5 \mathrm{~nm}$ compared to the 383 $\mathrm{nm}$ observed for the undoped $\mathrm{ZnO}$ NWs. This result is similar to the Ni-doped $\mathrm{ZnO}$ thin film. ${ }^{10}$ The ion doping may result in a weaker UV emission peak. From Figure 2, a weak broad band is observed at $\sim 510 \mathrm{~nm}$ for both undoped and doped NWs. This feature is commonly observed for $\mathrm{ZnO}$, which is attributed to oxygen deficiency. ${ }^{4 \mathrm{e}, 9}$

In summary, we show that by combining VLS growth and MEVVA doping, well-aligned Ni-doped $\mathrm{ZnO}$ NWs were obtained. After a proper annealing, the doped NWs have high crystallinity and little defects. The electrical conductivity was enhanced for over 30 times after doping. A red shift in PL peak of Ni-doped $\mathrm{ZnO}$ NWs was also observed. This research demonstrates a new approach for preparing aligned and doped NW arrays that have much improved electrical performance, which could be important for fabricating arrays of sensors, transistors, and photodetectors. The system will also be important for studying spin transport in $1 \mathrm{D}$ nanomaterials.

Acknowledgment. The research was supported by NSF, the NASA Vehicle Systems Program, and Department of Defense Research and Engineering (DDR\&E), the Defense Advanced Research Projects Agency (N66001-04-1-8903), National Science Council (NSC 93-2215-E-007-011), and Ministry of Education of Taiwan (91-E-FA04-1-4).

\section{References}

(1) (a) Gorla, C. R.; Emanetoglu, N. W.; Liang, S.; Mayo, W. E.; Lu, Y.; Wraback, M.; Shen, H. J. Appl. Phys. 1999, 85, 2595-2602. (b) Shibata, T.; Unno, K.; Makino, E.; Ito, Y.; Shimada, S. Sens. Actuators, A 2002, 102, 106-113. (c) Minne, S. C.; Manalis, S. R.; Quate, C. F. Appl. Phys. Lett. 1995, 67, 3918-3920.

(2) (a) Kind, H.; Yan, H. Q.; Messer, B.; Law, M.; Yang, P. D. Adv. Mater 2002, 14, 158-160. (b) Huang, M. H.; Mao, S.; Feick, H.; Yan, H.; Wu, Y.; Kind, H.; Weber, E.; Russo, R.; Yang, P. D. Science 2001, 292, 18971899. (c) Wang, Z. L. J. Phys.: Condens. Mater. 2004, 16, R829-R858.

(3) (a) Zhong, J.; Muthukumar, S.; Chen, Y.; Lua, Y.; Ng, H. M.; Jiang W.; Garfunkel, E. L. Appl. Phys. Lett. 2003, 83, 3401-3403. (b) Choi, H. J. Seong, H. K.; Chang, J. Y.; Lee, K.; Park, Y. J.; Kim, J. J.; Lee, S. K.; He, R. R.; Kuykendall, T.; Yang P. D. Adv. Mater. 2005, 17, 13511356. (c) Zheng, G. F.; Lu, W.; Jin, S.; Lieber, C. M. Adv. Mater. 2004, 16, 1890-1893. (d) Wen, J. G.; Lao, J. Y.; Wang, D. Z.; Kyaw, T. M.; Foo, Y. L.; Ren, Z. F. Chem. Phys. Lett. 2003, 372, 717-722. (e) Li, C. Zhang, D. H.; Lei, B.; Han, S.; Liu, X. L.; Zhou, C. W. J. Phys. Chem. $B$ 2003, 107, 12451-12455. (f) Li, S. Y.; Lin, P.; Lee, C. Y.; Tseng, T. Y.; Huang, C. J. J. Phys. D 2004, 37, 2274-2282. (g) Zhong, Z. H.; Qian, Q.; Wang, D. L.; Lieber, C. M. Nano Lett. 2003, 3, 343-346. (h) Lao, J. Y.; Wen, J. G.; Ren, Z. F. Nano Lett. 2002, 2, 1287-1291. (i) Radovanovic, P. V.; Barrelet, C. J.; Gradecak, S.; Qian, F.; Lieber, C. M. Nano Lett. 2005, 5, 1407-1411. (j) Hu, J. T.; Odom, T. W.; Lieber, C. M. Acc. Chem. Res. 1999, 32, 435-445.

(4) (a) Cebulla, R.; Wendt, R.; Ellmer, K. J. Appl. Phys. 1998, 83, 10871095. (b) Chopra, K. L.; Major, S.; Pandya, D. K. Thin Solid Films 1983, 102, 1-46. (c) Wang, R. P.; Sleight, A. W.; Cleary, D. Chem. Mater. 1996, 8, 433-439. (d) Jiménez-González, A. E. J. Solid State Chem. 1997 128, 176-180. (e) Wang, A. C.; Dai, J. Y.; Cheng, J. Z.; Chudzik, M. P.; Marks, T. J.; Chang, R. P. H.; Kannewurf, C. R. Appl. Phys. Lett. 1998 73, 327-329. (f) Ronning, C.; Gao, P. X.; Ding, Y.; Wang, Z. L.; Schwen, D. Appl. Phys. Lett. 2004, 84, 783-785.

(5) Brown, I. G.; Gavin, J. E.; MacGill, R. A. Appl. Phys. Lett. 1985, 47, $358-360$.

(6) Wagner, R. S.; Ellis, W. C. Appl. Phys. Lett. 1964, 4, 89-91.

(7) Wang, X. D.; Summers, C. J.; Wang, Z. L. Nano Lett. 2004, 4, 423-426.

(8) (a) Monteiro, T.; Boemare, C.; Soares, M. J.; Rita, E.; Alves, E. J. Appl. Phys. 2003, 93, 8995-9000. (b) Sonder, E.; Zuhr, R. A.; Valiga, R. E. J. Appl. Phys. 1988, 64, 1140-1144.

(9) Li, Q. H.; Wan, Q.; Liang, Y. X.; Wang, T. H. Appl. Phys. Lett. 2004, $84,4556-4558$.

(10) Qiu, D. J.; Wu, H. Z.; Feng, A. M.; Lao, Y. F.; Chen, N. B.; Xu, T. N. Appl. Surf. Sci. 2004, 222, 263-268.

JA0559193 